\title{
Construction of Adult Education Teaching Management System in Harmonious Society
}

\author{
Kun Cao \\ School of Humanities, Jilin Agricultural University, Changchun 130118, China \\ 763496763@qq.com
}

\begin{abstract}
With the idea of lifelong learning being put forward in our country, the historical mission of adult education is more important. As an important part of the national education, adult education has an irreplaceable important role in the construction of a harmonious society. This paper, carrying on the analysis of opportunities and challenges that the current adult education is facing, proposes the overall scheme for the implementation of adult education teaching management system, explains the design principle and content of database system, management process, related functions and business flow chart, and functions of each subsystem, and points out the problems needed to notice in the realization process of the system implementation scheme and requirements of the user jurisdiction design and so on. The management information system covers various functional components of adult higher education management, fully supports the network office mode, improves the work efficiency, and ensures the implementation of the network into adult education teaching management.
\end{abstract}

Keywords: Harmonious society; Adult education; Teaching management.

\section{Introduction}

The construction of a harmonious society is a profound social change, which has caused many profound changes in China's political, economic, cultural and other fields. The rapid development of computer multimedia technology, network technology and virtual reality technology, mankind information resources sharing has realized, which fundamentally changed the mode of information exchange in the past. The situation brought unlimited opportunities for the development of the modern education cause. And adult education, as the embodiment of Chinese lifelong education, is an important part of the education system of our country. In addition, the proposal of constructing harmonious society concept also change the adult education management thought [1]. From the education and teaching to the management service, people are sure of the important function of adult education. At the same time, they also see many practical problems in the teaching management of adult education. With the acceleration of the process of building a harmonious society in China, the reform of adult education management system is of great practical significance.

\section{Network Construction of Adult Education Management System in Harmonious Society}

\subsection{Problems Existing in the Traditional Adult Education Management System}

The traditional education and teaching management information system is the system that the system developer does not take the application of Internet into account in development. It includes both single machine system, file server system, and client / server system. Because of the shortcomings of the traditional system in the environment change, the shortcomings are gradually exposed. They are mainly: the traditional management information system is comparatively complex. Except for a lot of development at the server side, it is also necessary to largely develop in the clients' side [2]. To achieve different functions, it is required to re-develop the user interface. Additionally, in the traditional management information system, the system is usually confined to a single platform and a single product. Moreover, the use of traditional management information system is more complex that users need to be trained to learn. And because of the different developer's development style, the user interfaces of different developers are also of great difference. This allows users to learn to use a system, and they still need to re-learn when using the other system. 


\subsection{Network Formation Education and Teaching Management Process}

The content of adult education management information system is various and complex, but its management process is relatively stable. The basic management process of the system is shown in Figure 1, and the whole process can be divided into the following steps.

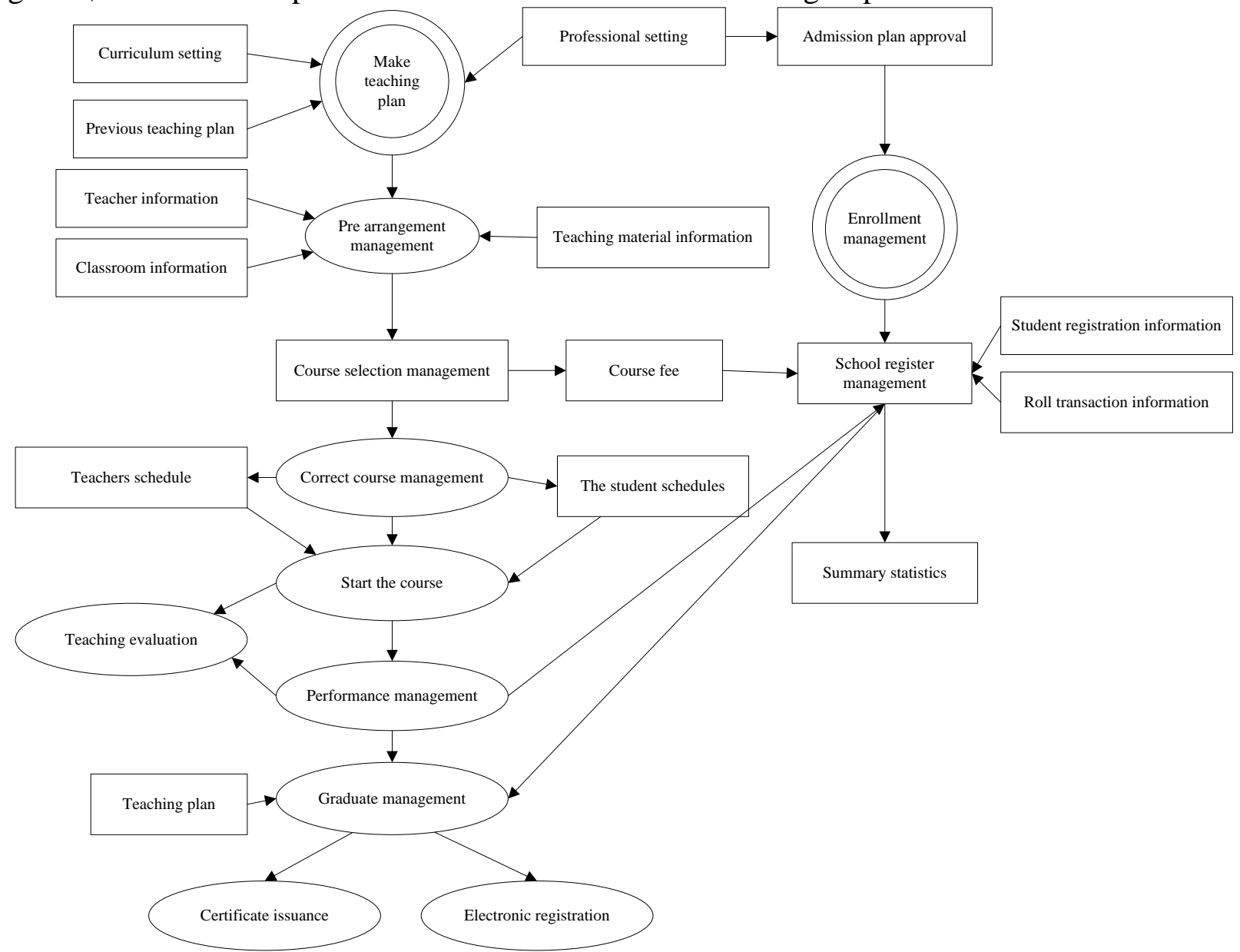

Figure 1 Flow chart of system management

(1) Import enrollment data into the system and form the basic information of students in school register management.

(2) Each teaching point, according to their own professional setting, curriculum setting or reference to previous teaching plan, develops annual enrollment professional teaching plan.

(3) According to the information of teachers, classrooms and teaching materials, the teaching staff of each teaching point arrange the course of the next semester in advance.

(4) Students can select in the course of the next semester in advance, carry out collective course selection through the Internet or the Senate to help.

(5) Before the commencement of the new semester, based on the courses of pre timetabling certain adjustments, form teacher's teaching and the students' course schedule.

(6) Give courses according to the teachers teaching and student's curriculum.

(7) Evaluate on the teaching quality according to the teaching situation of the teachers' curriculum and the course grade.

(8) In the process of teaching or after the knot, the teacher or the Senate register test or examination scores and the college audits students' scores.

(9) In the entire management process, the school management is involved in, student information provide data for other management links. In turn, data produced in other management aspects also becomes a part of the school information.

(10) The last part is the graduation management. According to the requirements of student enrollment, scores and the teaching plan, audit students' graduation qualification, and issue graduation certificate for students who pass through the qualification examination and approval and 
report data of graduates to the Department of Education in order to carry out education electronic registration.

\subsection{Network Teaching Management System Module Design}

\subsubsection{Network Educational Administration Management System}

Educational administration management is a project that has strong purpose, planning, scientific nature, normative and creativity. Proceed reasonable planning, organization, control, supervision, guidance and services to the process of teaching and learning, provide guarantee for the establishment of a stable teaching order and good teaching mechanism, and guarantee teaching work normally operate [3]. It is characterized by diversification of management object, complexity of management content, diversification of management information and comprehensive nature of management scope, and it is the core of the school management work, which is the center of the school teaching management work, playing a role of connecting link between the preceding and the following, left and right, communication between the internal and external.

(1) Enrollment management

Adult education enrollment has been networking. For those who need it, as long as they open the relevant page, enrollment information, introduction to the school and professional settings, especially the introduction to specialty professions and other related information are at a glance. It breaks through the geographical and time constraints, making school maximum and the fastest speed to publicizing the information of the College.

(2) School register management

In order to improve the adult education school register management level, standardize the management system of student status, making student information management better serve for various departments and various teaching, design and develop school register management system based on network. Only in this way can school, teaching, students be combined and form school register management mode of distributed management and centralized management.

(3) Teaching material management

Teaching materials management includes three modules: ordering of textbooks, distribution of materials, inventory management and the management of teaching materials and funds. The teaching material management process is shown in Figure 2.

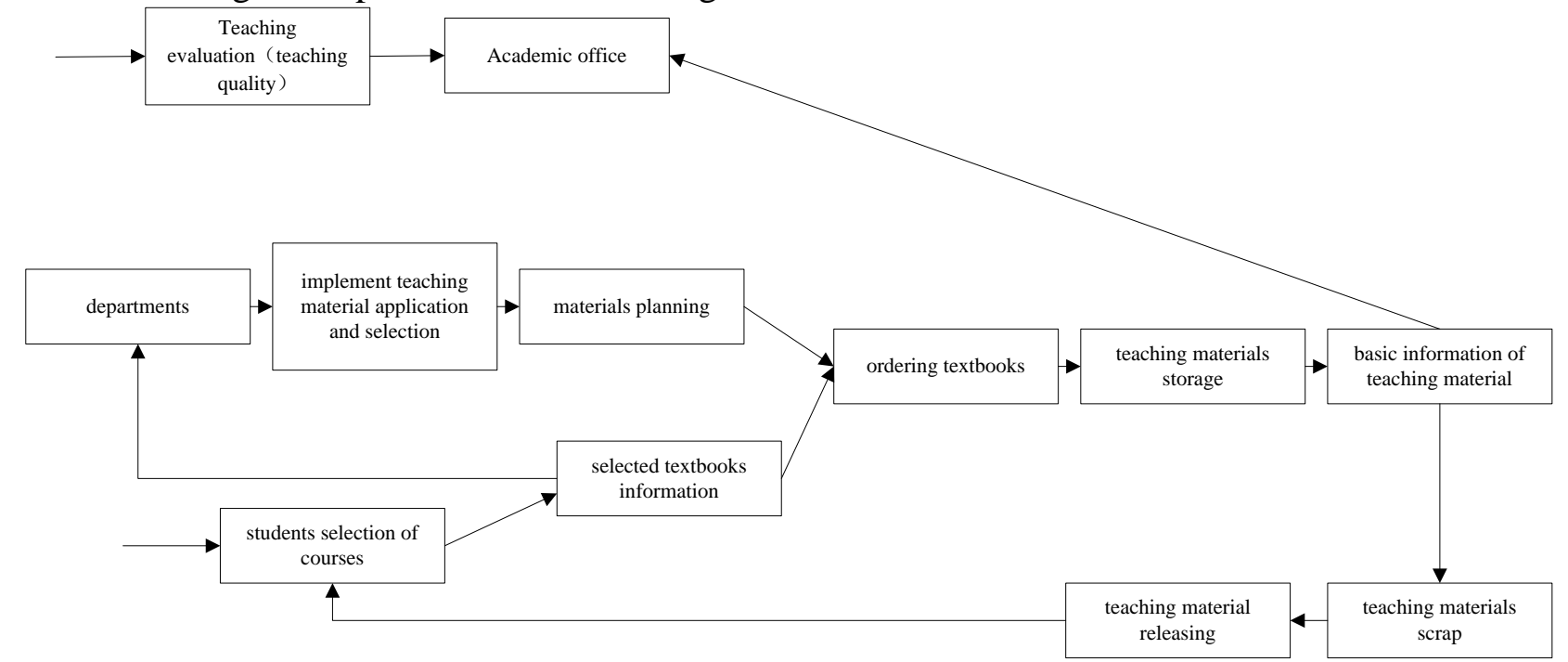

Figure 2 Teaching material management flow chart

(4) Professional and curriculum management

The specialty and curriculum management module includes four sub modules: specialty and curriculum setting, curriculum management, teaching content and plan release, and course selection management. Specific flow chart is shown in Figure 3. 


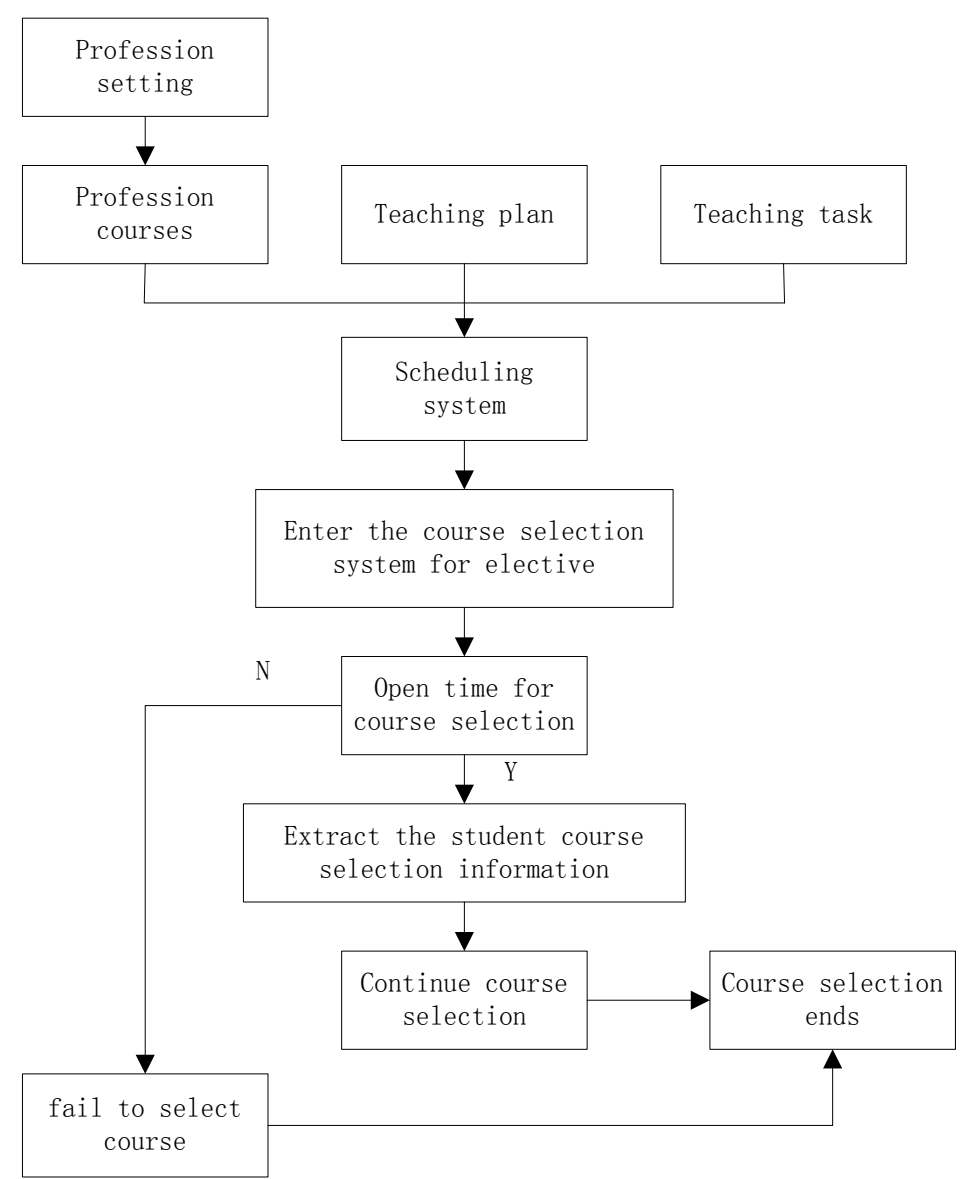

Figure 3 Flow chart of profession and curriculum management

(5) Examination management

Examination management is mainly managing for the exams that students will be tested in, which includes three functional modules of the final exam, make-up exam, and general exam. The basic flow chart is shown in Figure 4 [4].

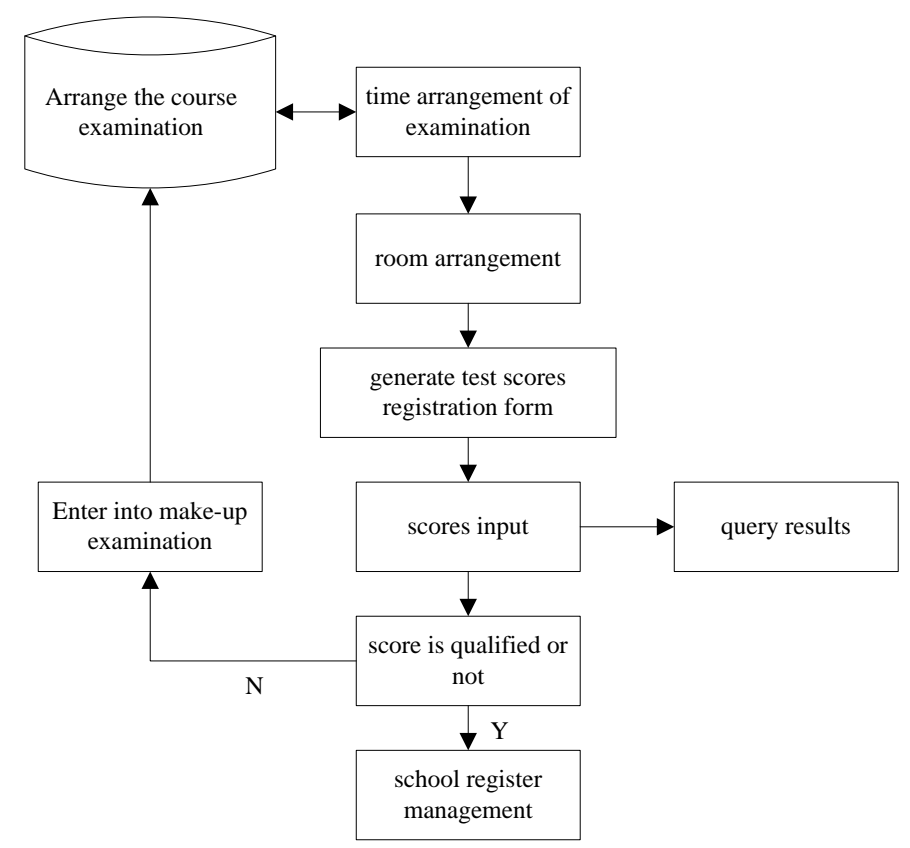

Figure 4 Examination management flow chart 
(6) Teaching evaluation management

The object of teaching evaluation includes the evaluation of teachers, curriculum and teaching materials in the process of classroom teaching. The weights and indicators of evaluation can be defined by custom settings by the users. The evaluation of teaching quality process flow chart is shown as Figure 5.

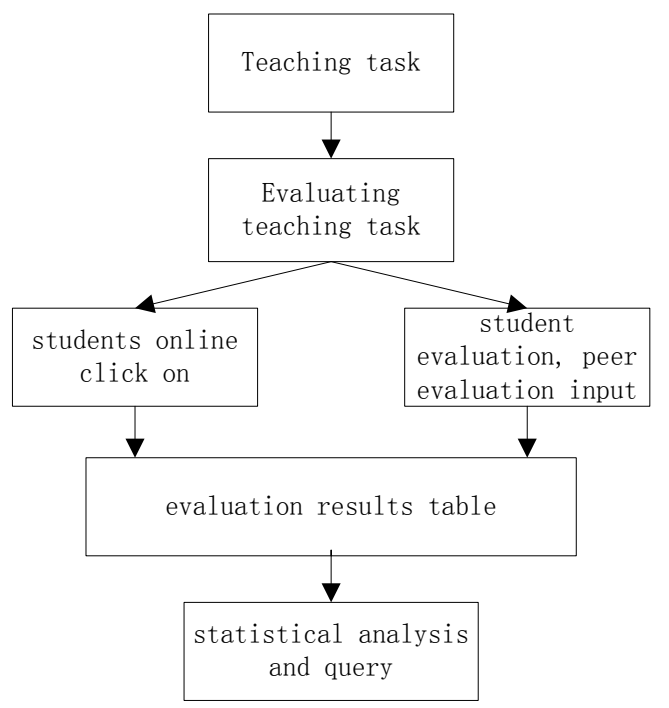

Figure 5 Teaching quality evaluation service flow chart

(7) Graduate management

Graduate management is mainly responsible for the graduate assistant information maintenance, graduation qualification, pre examination of academic degree and graduation result summary print and student card printing. Specific flow chart is shown in Figure 6.

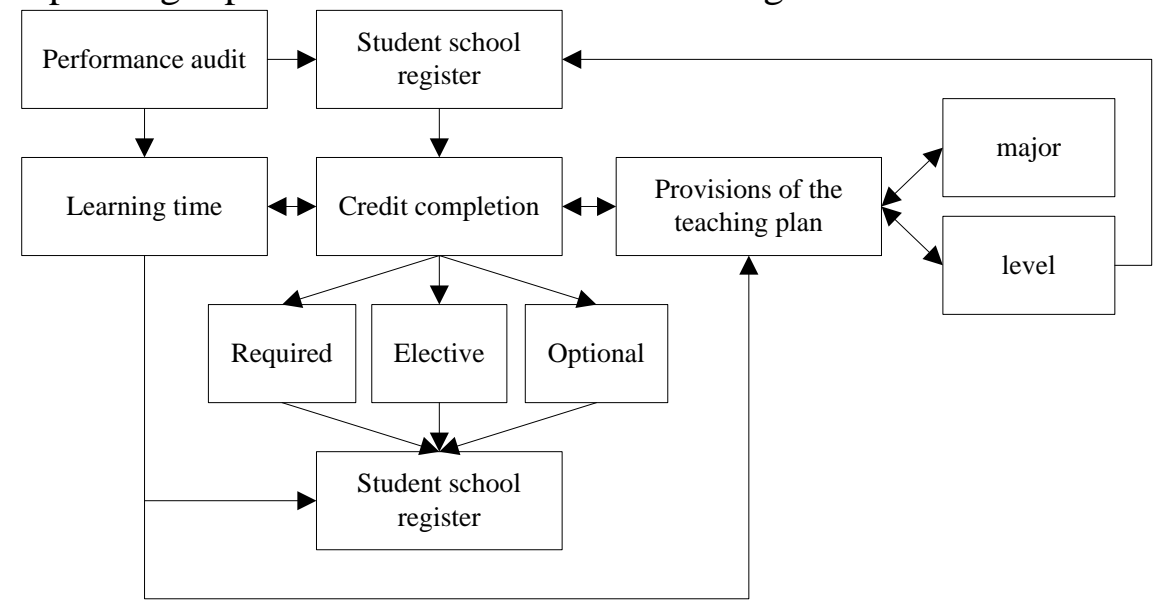

Figure 6 Graduation management flow chart

\subsubsection{Network Teaching System}

Network teaching system, including multimedia network teaching system, automatic question answering system, and online test system, which has a certain function and its own system resources.

(1) Multimedia network teaching system

Established based on the network, multimedia teaching system not only has all kinds of media information processing and human-computer interaction function. More importantly, it achieves the transmission of multimedia information on Internet and multimedia information resources sharing, forming a most ideal multimedia network teaching environment. Multimedia teaching process is shown in Figure 7. 


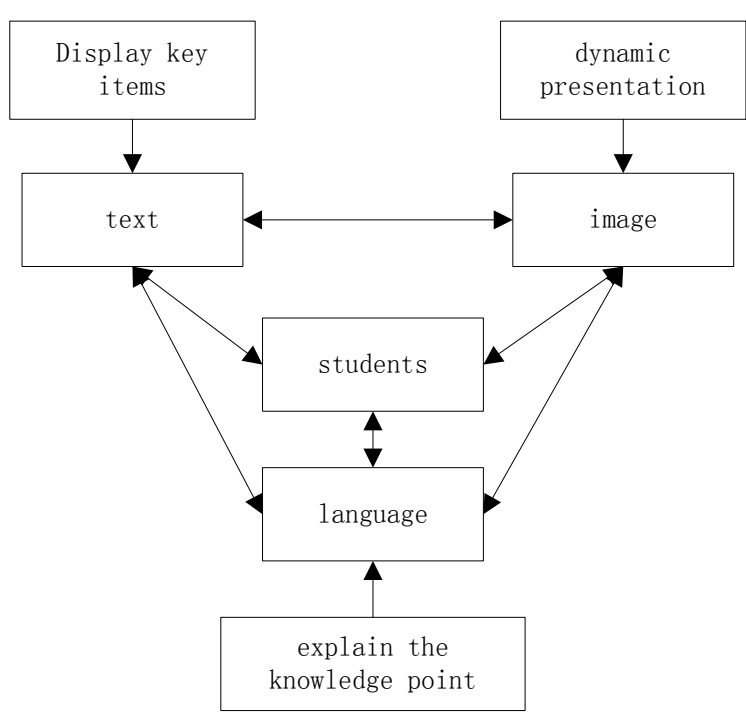

Figure 7 Multimedia class teaching process

(2) Automatic question answering system

Automatic question answering system is an adaptive knowledge base system, which is divided into two parts, automatic question answering and manual answering. The basic operation model of question answering system is shown in Figure 8.

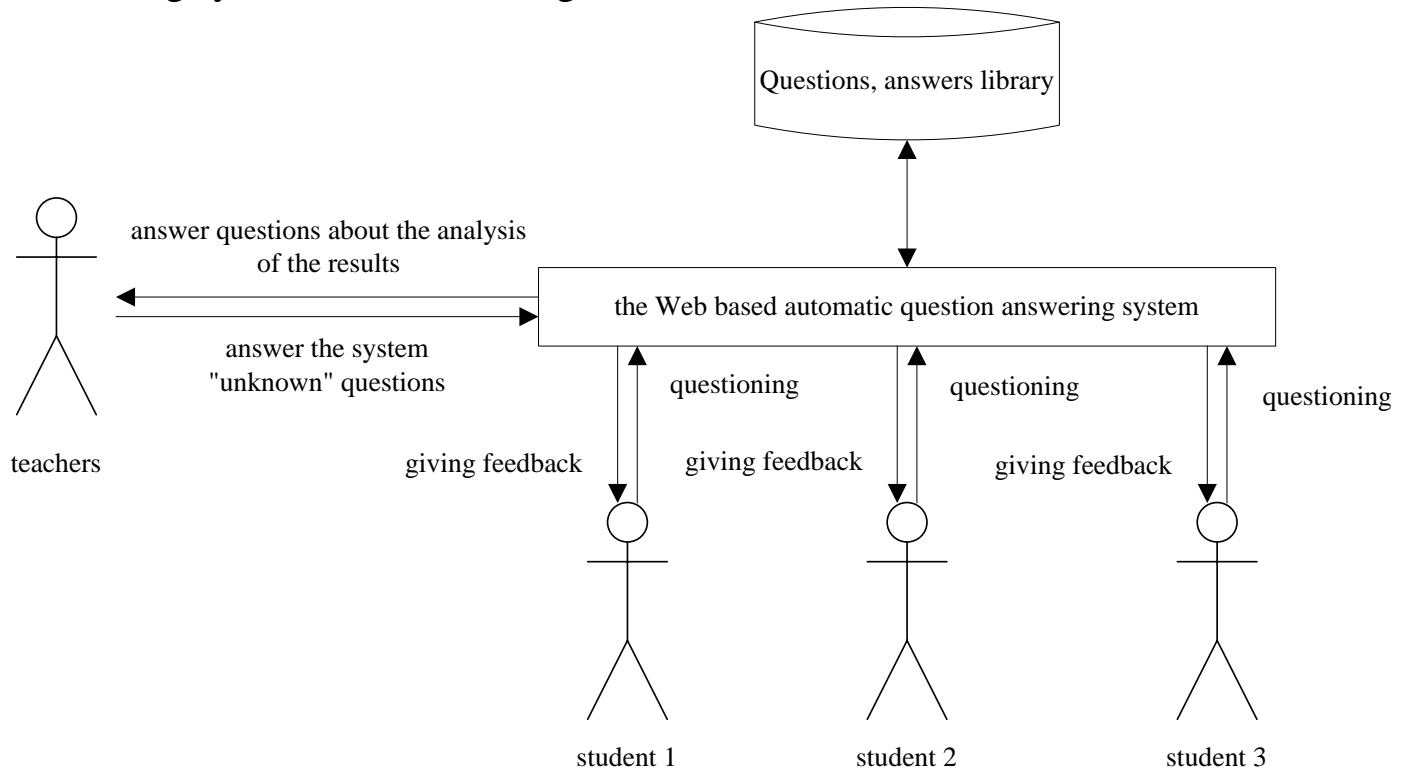

(3) Online test system

Figure 8 Operating model of answering system

Online test system comprises a test database, test paper generation tool (test paper), testing process control system and test results analysis tools, job layout and marking tools. Teachers in proceeding remote test and inputting corresponding test parameters in the browser, system will automatically compose the papers and the standard answer matched to the requirements. After the satisfactory papers are composed, it can be stored for formal papers for students. Additionally, students can input parameters according to their own learning situation, and form exercise papers for self-testing. And test functions include online examination, online marking and test results query.

\subsubsection{Integrated Information Inquiry System}

Integrated information inquiry system can help users to meet their own needs. Users can find the corresponding information in the appropriate use of the appropriate authority within the corresponding module. Through the educational administration management module, students can query selected classes department, class time, class location, class teachers and other information; through the examination management module, students can read exam grades, test scores, task scores, total rating grades and other information by semester according to the academic year [5]. If it is found 
that they did not pass a course, they can timely apply for make-up or rebuilt, and they can also recall the previous test papers, view the paper title and standard answer, answer record, teachers' score and so on.

\subsubsection{Safety Management System}

Management information system has comparatively perfect use function, but also possesses management system of maintaining system security. The security of the system should not only take into account the impact of the outside world, but also pay attention to the security problem brought about by internal application of data. At present, the management information systems based on network environment all set several security systems, and many popular operating systems and database management system have higher security level, coupled with firewall and intrusion detection system, it is believed that the computer network operating system is safe and reliable. Therefore, in the implementation of the network management information system, we should consider the application level security reliability, namely the security and reliability problems brought about by incomplete Web application itself.

\section{Conclusion}

Under the current situation of popular and lifelong education, adult education, as an important part of our country's higher education system, has obtained unprecedented developing opportunities. But for a long time, the adult education in our country has the shortcomings daunting task of management, weak management power, backward management means, low management inefficiency, low specification and standardization degree and so on. Information management has been in a relatively backward state, which has seriously restricted the development of adult education [6]. Based on the reasonable adult education teaching management information system, establish a more perfect network teaching management information system based on B / S structure and the C / S structure, optimizing and improving teaching management system of adult education, and improving office efficiency.

\section{References}

[1] Xie M R, Liu L. Thinking about Combination of Adult Education and Community Education in View of Harmonious Society [J]. Communication of Vocational Education, 2011.

[2] Xie K C. On the construction of teaching management system in vocational schools [J]. Journal of Nanchang College of Education, 2011.

[3] Tong Y R, Song P B. Construction of a Network-Based Open Experimental Teaching Management System [M]// Frontier and Future Development of Information Technology in Medicine and Education. Springer Netherlands, 2014:2807-2811.

[4] Guo J, Deng G, Wei Y. Discussion on the construction of Teaching Management Informatization in Higher Vocational Colleges[J]. Journal of Hubei Adult Education Institute, 2014, 126(6): págs. 2707-2716.

[5] Wang C. Construction of Management and Evaluation System of Engineering Education Teaching [J]. Times Agricultural Machinery, 2015.

[6] Xin-Rui L I, Bai-Hua L I. On the Construction of Modern Distance Education and the Lifelong Education System in China [J]. Modern Distance Education, 2012. 